\title{
Hormonal regulation of regucalcin gene expression: involvement in cell metabolism
}

\author{
Masayoshi Yamaguchi \\ Correspondence: yamamasa1155@yahoo.co.jp \\ Department of Hematology and Biomedical Oncology, Emory University School of Medicine, 1365 C Clifton Road, Atlanta, \\ GA 30322, USA.
}

\begin{abstract}
Regucalcin (RGN/SMP30) and its gene (rgn)are identified in over 15 species consisting of regucalcin family, and its gene is localized on X chromosome. Regucalcin has been shown to play a multifunctional role in many tissues and cell types. Hormonal regulations of regucalcin gene expression are mediated through various transcription factors (including AP-1, NF1-A1, RGPR-p117 and other), which are involved in phosphorylation and dephosphorylation by intracellular signaling factors. Regucalcin mRNA expression has been shown to be regulated by hormonal factors (including calcium, calcitonin, parathyroid hormone, 1,25-dihydroxyvitamin $\mathrm{D}_{3}$, insulin, tumor necrosis factor- $\alpha$, transforming growth factor- $\beta$, estrogen, testosterone, aldosterone, dexamethasone and other) in various tissues and many cell types. Regucalcin mRNA expression has also been shown to suppress with pathophysiological states that are related to hormonal diseases. Regucalcin may be a key molecule that is involved in hormonal effect and its related metabolic disease.
\end{abstract}

Keywords: Regucalcin, hormone, gene expression, cell signaling

\section{Introduction}

Calcium ion $\left(\mathrm{Ca}^{2+}\right)$ plays an important role as second messengers in regulation of many cell functions for hormonal stimulation. Calcium signal is partly transmitted to intracellular responses, which are mediated through a family of calcium-binding protein. The effect of calcium is amplified through calmodulin and protein kinase $C[\mathbf{1}, \mathbf{2}]$. Regucalcin was discovered in 1978 as a novel calcium-binding protein that differs from calmodulin and other calcium-related proteins $[3,4]$. The name regucalcin, was proposed for this calcium-binding protein that regulates the effect of calcium on cell functions [5-7]. After that, the protein named as senesence marker protein-30 (SMP30), which is identical to regucalcin, was reported in $1992[8,9]$.

The regucalcin gene has been found in many vertebrate and invertebrate species and is highly conserved in vertebrate species [10]. The regucalcin gene is localized on $X$ chromosome $[11,12]$. Regucalcin gene expression is regulated through various transcription factors (including AP-1, NF1-A1, RGPR-p117, $\beta$-catenin and other) [10]. Regucalcin protein and its gene are identified in over 15 species consisting of regucalcin family in vertebrate and invertebrate species [10].

Regucalcin has been shown to play a multifunctional role in cell regulation [reviewed in Refs. $[13,14]$; maintaining of intracellular calcium homeostasis, suppressions of $\mathrm{Ca}^{2+}$ dependent and -independent protein kinases and protein phosphatases, protein output, and nuclear deoxyribonucleic acid (DNA) and ribonucleic acid (RNA) synthesis. Regucalcin has also been shown to suppress cell proliferation and apoptotic cell death that is induced by various signaling factors $[13,14]$. Thus, regucalcin plays a pivotal role in maintaining cell homeostasis and function as a suppressor protein of intracellular signaling systems. Moreover, the pathophysiological role of regucalcin in metabolic disorder has also been shown; deficiency of regucalcin induces a liver fatty disease and overexpression of regucalcin induces osteoporosis and hyperlipidemia [15-17]. Regucalcin has been proposed to be a key molecule in cellular regulation and metabolic disease.

There is growing evidence that regucalcin gene expression is regulated through many hormonal actions, which are involved in metabolic regulation. Hormonal regulation of regucalcin gene expression may be mediated through various transcription factors. Regucalcin may participate in revelation of hormonal effect that regulates cell metabolism. This review has been written to outline the recent advances that have been made concerning hormonal regulation on regucalcin gene expression in vertebrate species and will discuss an involvement in the role of regucalcin in metabolic regulation and disorder.

\section{Cell signaling factors and its related transcription factors}

Regucalcin gene expression has been shown to regulate through various intracellular signaling factors that are involved in hormonal stimulation. Various transcription factors, which are related to this process, have been identified.

\section{Promoter of the regucalcin gene}

The regucalcin gene has been found in many vertebrate and invertebrate species and is highly conserved in vertebrate species including human, monkey, rat, mouse, dog, bovine, rabbit and chicken $[10,18]$. The regucalcin gene is localized on $\mathrm{X}$ chromosome [11,12]. The $5^{\prime}$-untranslated region of the regucalcin gene is encoded by the exon I ( 429 bases) and 16 bases of the exon II, and the coding region is present in from the exon II to the exon VII containing the $3^{\prime}$-untranslated region [19]. The rat 
regucalcin gene consists of seven exons and six introns with the size more than $18 \mathrm{~kb}$. The chromosomal assignment of the regucalcin gene is located at q11.1-12 proximal end of rat chromosome X [11] and human chromosome Xp 11.3-Xp 11.23 , which is suggested as a candidate gene for an X-linked metabolic disease mapping in this region, includes the gene that codes regucalcin [12]. Regucalcin is expressed in various tissues with the size of $1.7 \mathrm{~kb}$ mRNA $[20,21]$.

The nuclear protein component has been found to specifically bind to the fragment II (BstXI-BstXI) containing the upstream region from the first exon of rat regucalcin gene $[22,23]$. The putative cis-acting elements that contain CAAT-box AP-2 and AP-4 are located in this region [22,23]. The promoter activity in the $5^{\prime}$-flanking region (the upstream from the first exon of the rat regucalcin gene) has been characterized to understand the mechanism underlying the regulation of regucalcin gene expression [23]. The region $-102 /+18$ was an essential for basal functional promoter activity of the rat regucalcin gene [23]. Both a TATA-like sequence and a CCAAT box locates between nucleotides -102 and +18 , which play an important role in determining basal promoter activity of the rat regucalcin gene [23].

\section{Involvement of AP-1}

The transcription factor AP-1 has been found to relate in enhancement of regucalcin gene expression after calcium administration. The expression of regucalcin mRNA in the liver has been found to markedly enhance after administration of calcium chloride solution in rats [20]. Calcium administration caused binding of AP-1 to the fragment II region of rat regucalcin gene [24]. A potential sequence of the AP-1-binding site is seen in the fragment II region -710/-575 of the rat regucalcin gene $[\mathbf{2 2}, 23]$. In many cells, AP-1, which consists of homo- and/or hetero-dimers of the c-jun and c-fos gene products, regulates the expression of genes that contain specific AP-1-binding sites, named phorbol-12-myristate13-acetate (PMA)-responsive element [25]. Treatment with PMA has been found to stimulate luciferase activity from $-710 /+157$ LUC plasmid in cloned rat hepatoma cells (H4-II-E), which express regucalcin mRNA [23]. PMA has been reported to activate transcription due to regulating AP-1 binding [26]. AP-1 has been known to regulate the expression of some genes that contain specific AP-1 binding sites, a PMA-responsive element [27]. The elevation of activity of protein kinase $C$, which is activated by PMA, may lead to activation of DNA binding activity of AP-1 on the regucalcin gene promoter region.

Insulin has been shown to enhance regucalcin gene expression. Insulin stimulated regucalcin promoter activity in cloned rat hepatoma $\mathrm{H} 4-\mathrm{II}-\mathrm{E}$ cells, which is mediated through a cis-acting sequence(s) located between nucleotides -710 and -343 of the rat regucalcin gene [23]. Insulin-inducible nuclear protein(s) may mediate stimulatory effects of insulin on the regucalcin promoter activity. Insulin has been known to stimulate the AP-1-mediated gene expression [27].
Phosphorylation of AP-1 with insulin treatment plays an important role in hormonal regulation of regucalcin gene expression.

Treatment with dibutyryl cyclic adenosine monophosphate (dibutyryl cAMP), which is the second messenger for peptide hormone stimulations, has been shown to increase the regucalcin promoter activity in H4-II-E cells [23]. The CAMPsensitive nuclear protein, which specifically binds to the region $-342 /+58$ of the rat regucalcin gene, has been demonstrated using gel mobility shift assays [23]. The identified trans-acting factors may be involved in stimulation of regucalcin gene promoter activity that is mediated through cAMP signaling. Transcriptional responses to CAMP signaling are most commonly mediated through cAMP response element [28] and AP-2 element [29]. The region between nucleotides -342 and +58 of the rat regucalcin gene contains the potential AP2-binding sites. However, AP-2 was not involved in dibutyryl CAMP-induced formation of complex in the region $-342 /+58$ [23]. Binding of the identified cyclic AMP-inducible nuclear protein to the regucalcin gene may be mediated through signaling pathways that are related to CAMP-dependent protein kinase [23].

Thus, the existence of trans-acting factors responsible for $\mathrm{Ca}^{2+}$, CAMP, PMA and insulin on the regucalcin gene has been identified in the promoter region of the rat regucalcin gene. AP-1 has been demonstrated to be important as a transcription factor for the regucalcin gene expression. AP-1, which can bind to the $5^{\prime}$-flanking region of the regucalcin gene, may

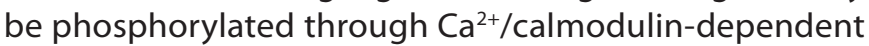
protein kinase, protein kinase $C$, and tyrosine kinase [31-33].

\section{Involvement of NF1-A1}

A nuclear factor 1 (NF1) consensus motif TTGGC(N) ${ }_{6} \mathrm{CC}$ is found between position -523 and -506 in the $5^{\prime}$-flanking region of the rat regucalcin gene [34]. NF1-like sequence-binding proteins, which are distanced from NF1, have been reported in a1 (I) collagen promoter [35], bone sialoprotein promoter [36], glial fibrillary acidic protein promoter [37], and rat p53 promoter [38]. Hepatic regucalcin promoter activity and regucalcin mRNA expression has been shown to up regulate after culture with Bay K8644, PMA, and insulin [31-33]. The $5^{\prime}$-flanking region of rat regucalcin gene, which is enhanced by these mediators, was located in -710 to -343 [23]. The cisacting DNA sequence, which mediates the effect of Bay K8644, PMA and insulin in increasing the regucalcin gene promoter activity, may be located in the NF1-like sequence (TTGGC) of the regucalcin gene in $\mathrm{H} 4-\mathrm{II}-\mathrm{E}$ cells. Gel mobility shift assay with TTGGC oligonucleotide, which is located between position -523 and -506 in the promoter region, showed that this region contains a nuclear factor I (NF1) consensus motif TTGGC(N) ${ }_{6} \mathrm{CC}[39]$.

The binding of nuclear protein to TTGGC oligonuecleotide with the gel mobility shift assay was enhanced after treatment of vanadate, an inhibitor of protein tyrosine phosphatase 
[40], and adenosine triphosphate (ATP), which is a substrate of protein phosphorylation [39]. Binding of nuclear protein to the TTGGC sequence of regucalcin gene promoter may related to protein phosphorylation. Nuclear protein binding to TTGGC sequence was depressed by various inhibitors of $\mathrm{Ca}^{2+} / \mathrm{calmodulin}$ dependent protein kinas, protein kinase $\mathrm{C}_{\text {, }}$ protein tyrosine kinase, mitogen-activated protein (MAP) kinase or phosphatidylinositol-3 (PI3) kinase, supporting the view that nuclear protein binding to TTGGC sequence may be mediated through various protein kinases [39]. Transcription factor, which binds to TTGGC motif in the rat regucalcin gene promoter, was found to be a NF1-A1 from a rat liver CDNA library [41]. The expression of NF1-A1 mRNA is seen in the liver, kidney, heart, spleen and brain of rats [41]. NF1-A1 may be related to the tissue-specific expression of regucalcin mRNA in the liver and kidney.

Thus, AP-1 binds to the region $-710 /-575$ in the rat regucalcin gene promoter region and NF1-A1 binds to the region -523 and -506 . The multi-transcription factor (including AP-1 and NF1-A1) may be related to tissue specific expression of the regucalcin gene in rats. Binding of these factors to the regucalcin gene is regulated through phosphorylation and dephosphorylation by various protein kinases and phosphatases.

\section{Involvement of RGPR-p117}

NF1-A1 has been shown to be a transcriptional factor that stimulates the rat regucalcin gene promoter activity [41]. Moreover, a novel transcription factor, which binds to the TTGGC motif of regucalcin gene, has been identified using a yeast one-hybrid system $[\mathbf{4 2 , 4 3 ]}$. This protein was termed as a regucalcin gene promoter region-related protein (RGPR-p117) $[43,44]$. Enhancement of regucalcin mRNA expression in RGPRp117-overexpressing NRK52E cells was depressed in presence of staurosporine, an inhibitor of protein kinase C [44]. However, this enhancement was not depressed in presence of dibucaine, an inhibitor of $\mathrm{Ca}^{2+} / \mathrm{calmodulin}^{-}$dependent protein kinase, or PD98059, an inhibitor of mitogen-activated protein (MAP) kinase, wortmannin, an inhibitor of PI 3-kinase, or genistein, an inhibitor of protein tyrosine kinase $[45,46]$. The effect of RGPR-p117 in enhancing the regucalcin promoter activity is clearly mediated through phosphorylation with protein kinase C. Vanadate and okadaic acid are inhibitors of protein phosphatases [40]. Enhancement of the regucalcin gene promoter activity in RGPR-p117-overexpressing NRK52E cells was inhibited after culture with vanadate [46]. This effect was not observed in case of okadaic acid, an inhibitor of protein serine/threonine phosphatase. Participation of protein tyrosine phosphatases is also suggested in the enhancing effect of RGPR-p117 on regucalcin promoter activity.

\section{Involvement of other transcription factors}

As described above, various transcription factors are participated in stimulation of the regucalcin gene expression related to hormonal signaling factors. Other transcription factors have also been reported in the gene expression.

$\beta$-Catenin has been shown to enhance regucalcin gene expression due to verifying a functional TCF-4-binding site that is located between -163 and -157 (CTTTGCA) in the regucalcin promoter to be critical for regulation by $\beta$-catenin [47]. $\beta$-Catenin may be a signaling factor that enhances regucalcin gene expression in liver cells.

Culture with tumor necrosis factor- $a$ (TNF- $a$ ) has been shown to suppress regucalcin mRNA expression in osteoblastic MC3T3-E1 cells [48]. TNF- $\alpha$ activates NF-KB signaling in the cells. Activation of NF-KB signaling may depress regucalcin gene promoter activity in the cells. The consensus sequences (CGGAAAGTCCA) of transcriptional factor binding sites for NF-KB signaling are seen in the region between -356 and -347 or -66 and -57 of regucalcin promoter [23].

The expression of hepatic regucalcin mRNA has been shown to stimulate after administration of $17 \beta$-estradiol, which its receptor is localized in the nucleus of rats [49], suggesting the existence of an estrogen response element [ERE; G(T)GTCA]-linked promoter in the regucalcin gene promoter region [50]. Administration of $17 \beta$-estradiol has been shown to down-regulate regucalcin mRNA expression in rat mammary gland and prostate [51]. The region $-710 /+157$ of the rat regucalcin gene ligated to the luciferase reporter gene did not show estradiol responsiveness [23]. There was not seen difference in binding pattern between the nuclear extracts from control or estradiol-treated cells in gel mobility shift experiments [23]. The cis-acting element for estradiol may locate in the sequence upstream from the position -710 in the promoter region of regucalcin gene.

Existence of androgen-responsive-elements consensus sequences has also been found to be at $-906,-915,-4126$, and -5822 bp upstream from the transcription initiation site of regucalcin promoter region [51].

Promoter activity of the regucalcin gene in $\mathrm{H} 4-\mathrm{II}-\mathrm{E}$ cells has been found to enhance after treatment of dexamethasone [23]. $5^{\prime}$-Deletion analysis indicated that the dexamethasone response sequence was located within region -342/+157 of the rat regucalcin gene [23]. A potential glucocorticoid response element, however, is not present in this region $[23,30]$. Dexamethasone-inducible nuclear protein, which binds to region $-342 /+58$, was not detected by gel mobility shift experiments [23]. Other regulatory mechanisms may involve in stimulation of regucalcin gene promoter activity with dexamethasone.

In addition, transcriptional factor binding sites for $\mathrm{CdxA}$, GATA2 and SRY are present in the region between -513 and -352 of regucalcin promoter has been reported [54]. Mutation in SRY site (-403/-368) showed a maximum increase in reporter activity, suggesting that SRY like protein may be acting as a repressor of the regucalcin gene along with CdxA and GATA-2 [54]. Transcriptional binding sites for Sp1 (172/-148 bp) and a C/EBP beta (-190/-177 bp) in the regucalcin gene promoter may also be involved in depression of the promoter activity 
Masayoshi Yamaguchi Hormonal Studies 2013,

[54]. The identification of signaling factors that suppress regucalcin gene expression, however, remains to be elucidated.

\section{Hormonal regulation in liver regucalcin gene expression}

Various transcription factors have been shown to involve in regulation of regucalcin gene expression in cells. This process is mediated through various signaling pathways that are stimulated with cytokine, peptide hormone, and steroid hormone in cells. In fact, various hormones have been shown to regulate regucalcin mRNA expression in vivo, suggesting that regucalcin is involved in cell regulation that is mediated through hormonal action.

\section{Calcium administration stimulates regucalcin mRNA expression in vivo}

Calcium plays a hormonal role in various cell types. A single intraperitoneal administration of calcium chloride solution (15 $\mathrm{mg}$ calcium $/ 100 \mathrm{~g}$ body weight) in rats induced a remarkable increase in regucalcin mRNA in the liver; the level was about $200 \%$ of control at 30 minutes after the administration [20]. Subsequently, it's expression level began to decrease with time and reached about $40 \%$ of control level at 120 minutes after the administration [20]. The expression of regucalcin mRNA rapidly responds to calcium administration. Liver regucalcin concentration was increased after a single oral administration of calcium chloride ( $25-75 \mathrm{mg}$ calcium/100 g) in rats; this increase was seen at 30 minutes after the administration and its level reached to maximum at 120 minutes, and then began to decrease [55]. This increase may be result from elevation of hepatic regucalcin mRNA expression, and also the metal may partly influence on regucalcin synthesis at translational process in liver cells after calcium administration in rats.

In fact, administration of calcium caused an increase in calcium content in the liver of rats. Calcium signaling may play a role in enhancement of regucalcin mRNA expression in liver cells. A single intraperitoneal administration of zinc, copper or cadmium with a dose of $0.374 \mathrm{mmol} / 100 \mathrm{~g}$ body weight did not cause an appreciable increase in regucalcin mRNA levels in the liver of rats [20]. Regucalcin mRNA expression was uniquely stimulated by calcium among various metals. Administration of TFP $(5.0 \mathrm{mg} / 100 \mathrm{~g})$ completely prevented the stimulatory effect of calcium treatment on regucalcin mRNA expression in the liver of rats [56], suggesting that this expression is activated through a certain intermediate protein that is phosphorylated through $\mathrm{Ca}^{2+} /$ calmodulindependent protein kinase.

Regucalcin mRNA is expressed from earlier stages of development of the liver of fetal rats. This expression is enhanced through intake of calcium. Hepatic regucalcin mRNA expression was progressively increased in fetal development of rats, when the gene expression was analyzed at 8,15 , and 21 days of pregnancy [57]. Regucalcin mRNA expression in the fetal liver was seen at 15 days of pregnancy with fetal formation, and the gene expression was increased in fetal development (21 days of pregnancy) [57]. Increasing age caused an increase in regucalcin mRNA expression in the livers of newborn rats and weanling rats [57]. A single oral administration of calcium $(50 \mathrm{mg} / 100 \mathrm{~g})$ to maternal rats caused an increase in the transport of calcium into the fetal rats, and regucalcin mRNA expression in the fetal liver was markedly (about 2-fold of control) enhanced [57].

Finding, that liver regucalcin expression is increased after oral administration of calcium in rats, suggests a physiological significance in aspect of calcium metabolism in the liver. A rapid increase in serum calcium concentration brings on excretion into the hepatic bile of rats [58-60]. Liver metabolism is regulated by an increase in $\mathrm{Ca}^{2+}$ in the cytoplasm of liver cells due to hormonal stimulation $[\mathbf{1 , 2}]$. Since regucalcin protein is increased after an increase in liver cytosolic $\mathrm{Ca}^{2+}$ concentration, the protein may play a regulatory role in the reversibility of liver cell functions related to $\mathrm{Ca}^{2+}$. Regucalcin has been shown to reverse activation and inhibition of many enzymes by $\mathrm{Ca}^{2+}$ in liver cells [6]. These findings support the view that regucalcin plays a physiological role in regulation of calcium homeostasis in liver cells.

Dietary intake may have an effect on regucalcin gene expression. Hepatic regucalcin mRNA expression has been shown to decrease after fasting of rats [61]. Re-feeding markedly enhanced regucalcin mRNA expression reduced in the liver of fasted rats [61]. Hepatic regucalcin mRNA expression was increased after oral administration of glucose to fasted rats [61]. Glucose may be a stimulatory factor in the expression of regucalcin mRNA in the liver [61]. Administration of insulin ( 1 and $10 \mathrm{U} / 100 \mathrm{~g}$ body weight) caused a remarkable elevation of regucalcin mRNA expression in the liver of fasted rats [61], suggesting that increased mRNA expression with feeding is partly resulted from secretion of insulin. The effect of insulin on regucalcin mRNA expression may be involved in protein phosphorylation by tyrosine kinase linked with insulin receptor in rat liver cells [33]. Overexpression of regucalcin in modeled hepatoma H4-II-E cells has been shown to reveal insulin resistance [17].

Regucalcin gene expression has been shown to enhance liver regeneration with proliferating cells. Adult rat hepatocytes are normally quiescent in vivo; however, 20-30 hours after partial hepatectomy (two-thirds), they undergo a synchronous wave of DNA synthesis and cell division and continue to divide until the original mass of the liver is regenerated 5-7 days late. Liver weight, which is reduced after partial hepatectomy (about 70\%), is restored at 3 days after surgery [62]. Regenerating liver increased calcium content [62]. Liver regucalcin mRNA expression was increased 1-5 days after hepatectomy as compared with that of sham-operated rats, which is at the time point during activation of liver proliferation with a longer time (5 days) [62]. The increase in regucalcin mRNA expression in regenerating liver may be related to suppression of over-proliferation of liver cells. Calmodulin 
is increased during activation of proliferation of liver cells after partial hepatectomy [63]. The increase in calmodulin synthesis in regenerating rat liver is observed at 8 hours after

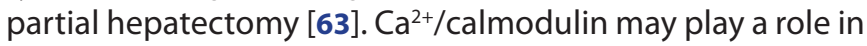
proliferation of liver cells. The increase in regucalcin mRNA expression after partial hepatectomy was weakened after a single intraperitoneal administration of TFP, an inhibitor of $\mathrm{Ca}^{2+} /$ calmodulin [63]. Regucalcin mRNA expression in regenerating liver may be mediated through $\mathrm{Ca}^{2+} / \mathrm{calmodulin}$ in rat liver. Hepatocyte growth factor, which promotes liver regenerating after partial hepatectomy, has been shown to increase calcium concentration in rat hepatocytes [64].

Calcitonin, a hypocalcemic hormone, is secreted from the thyroid glands due to an increase in serum calcium concentration. Calcitonin can stimulate calcium inflow into liver cells $[\mathbf{5 8 , 5 9 ]}$, and the hormone increases excretion of calcium into the hepatic bile of rats [60]. Hypercalcemia after a single oral administration of calcium induced a rapid increase in calcium content and regucalcin mRNA levels in the liver of rats [65]. These increases were not seen in thyroparathyroidectomized (TPTX) rats [65]. Endogenous calcitonin may participate in an increase in hepatic regucalcin mRNA expression after administration of calcium.

The sex-steroid hormone, $17 \beta$-estradiol binds the estrogen receptors (ERs, a or $\beta$ ) in target cells. These nuclear hormone receptors belong to the subfamily of ligand-regulated transcription factors. A single subcutaneous administration of $17 \beta$-estradiol (50, 100 and $200 \mu \mathrm{g} / 100 \mathrm{~g}$ body weight), a steroid hormone which is related to nuclear receptor, has been shown to induce a remarkable increase in regucalcin mRNA in the liver of rats; the level was increased about $200 \%$ of control at 24 hours after the dose of $200 \mu \mathrm{g} / 100 \mathrm{~g}$ [50]. Hepatic regucalcin mRNA expression was not altered after a single subcutaneous administration of thyroxine $\left(\mathrm{T}_{4}\right)$ $(2,4$ and $8 \mathrm{mg} / 100 \mathrm{~g})$ or hydrocortisone $(1$ and $3 \mathrm{mg} / 100 \mathrm{~g})$ in rats [50]. The enhancement of hepatic regucalcin mRNA expression after $17 \beta$-estradiol administration may be involved in an increase in the estrogen response element [ERE; G(T) GTCA]-linked promoter activity [50]. However, ovariectomy did not cause a significant change in regucalcin mRNA expression in the liver of female rats [66]. The subcutaneous administration of $17 \beta$-estradiol ( $200 \mu \mathrm{g} / 100 \mathrm{~g}$ body weight) in ovariectomized rats did not cause an appreciable increase in hepatic mRNA expression [66]. A physiological significance, which $17 \beta$-estradiol stimulates liver regucalcin gene expression, is unknown. However, regucalcin may participate in the regulation of cell metabolism that is related to estrogen effect on liver.

\section{Hormonal regulation in kidney regucalcin mRNA expression}

Regucalcin is also expressed in the kidney cortex but not the medulla of rats $[67,68]$. Kidney plays a physiological role in regulation of calcium homeostasis in blood by re-absorption of urinary calcium. Kidney cortex constitutes nephron including glomerula and tubula. Regucalcin in the kidney cortex may be involved in a physiological function, which is related to calcium homeostasis, in the glomerular filtration and tubular re-absorption.

Regucalcin mRNA expression in the kidney cortex was increased after a single intraperitoneal administration of calcium chloride solution ( $5-15 \mathrm{mg}$ calcium $/ 100 \mathrm{~g}$ body weight) in rats; this increase was remarkable at 60-120 minutes after the administration [67]. Calcium administration produced a remarkable increase in serum calcium concentration and a significant elevation of calcium content in the kidney cortex during 20 minutes after the administration [67]. The increase in regucalcin mRNA expression in the kidney cortex was seen at 60 minutes after calcium administration in rats [67]. The increase in regucalcin mRNA expression may be related to calcium accumulated in the kidney cortex after calcium administration. Thus, regucalcin gene expression has been shown to enhance through an increase in calcium in the kidney cortex cells. Regucalcin may also regulate calcium effect on cellular function that is influenced by re-absorption of calcium in kidney cells, since the role of regucalcin may be in regulation of liver cell function related to effect of calcium.

The expression of regucalcin mRNA in the kidney cortex was also stimulated after calcium administration in TPTX rats with deficiency of calcium-regulating hormones [calcitonin and parathyroid hormone (PTH)] that are secreted from thyroidparathyroid glands [67]. A single subcutaneous injection of calcitonin (10-100 MRC mU/100 g) or PTH (1-10 U/100 g) in TPTX rats administered with calcium $(10 \mathrm{mg} / 100 \mathrm{~g})$ did not cause an appreciable alteration of regucalcin mRNA levels in the kidney cortex [67]. The increase in regucalcin mRNA expression after calcium administration was completely blocked after administration of TFP $(5 \mathrm{mg} / 100 \mathrm{~g})$ [67]. Regucalcin mRNA expression in the kidney cortex may be mediated through signaling mechanism that is involved in activation of $\mathrm{Ca}^{2+} /$ calmodulin-dependent protein kinase. The nuclear proteins in kidney cortex have been found to specifically bind to the fragment-II in the promoter region of rat regucalcin gene [68]. The formation of nuclear protein components was enhanced through $\mathrm{Ca}^{2+}$ signaling-dependent process [69]. These nuclear protein components may be AP-1, NF1-A1 and RGPR-p117.

Hormonal regulation of regucalcin gene expression has been shown using cloned normal rat kidney proximal tubular epithelial NRK52E cells in vitro. PTH, 1,25-dihydroxyvitamin $\mathrm{D}_{3}$ or calcitonin plays a role in regulation of calcium transport in the kidney proximal tubular epithelial cells. PTH has a stimulatory effect on re-absorption of calcium in the kidney proximal tubule. Among these hormones, PTH has been shown to stimulate regucalcin mRNA expression and its protein level in NRK52E cells [70]. Regucalcin may play a physiological role as a key molecule in the re-absorption of calcium in the kidney proximal tubule. The effect of PTH on re-absorption 
Masayoshi Yamaguchi Hormonal Studies 2013,

of urinary calcium may be mediated through regucalcin. The effect of PTH in stimulating regucalcin mRNA expression in NRK52E cells has been shown to mediate through signalling pathways that are related to CAMP or protein kinase C [70], and it may be not involved in cell signalling that is related to protein tyrosine phosphatase [70]. PTH has been shown to enhance nuclear translocation of RGPR-p117, a transcription factor, to stimulate regucalcin gene expression in NRK52E cells $[45,46,70]$.

Interestingly, regucalcin mRNA expression has been found to suppress after culture with TNF- $a$ or transforming growth factor- $\beta$ (TGF- $\beta$ ) in NRK52E cells [71]. Signalling factors, which depress regucalcin mRNA expression, have been poorly understood. This physiological significance of suppression of regucalcin gene expression remains to be elucidated.

The effect of various steroid hormones on regucalcin mRNA expression in the kidney cortex of rats has been shown. Rats received a single subcutaneous administration of steroid; the animals were sacrificed 60 minutes after administration of aldosterone $(2.5,5$ and $10 \mu \mathrm{g} / 100 \mathrm{~g}$ body weight) or 6 hours after administration of estrogen (17 $\beta$-estradiol; 50,100 and $200 \mu \mathrm{g} / 100 \mathrm{~g})$, hydrocortisone $(0.5,1.0$ and $3.0 \mathrm{mg} / 100$ g), and dexamethasone (50, 100 and $150 \mu \mathrm{g} / 100 \mathrm{~g}$ ) [72]. Administration of aldosterone or estrogen with an effective dose in rats caused an appreciable decrease in regucalcin mRNA expression in the kidney cortex [72]. Hydrocortisone administration did not have an effect on regucalcin mRNA expression in the kidney cortex [72].

Aldosterone has a stimulatory effect on sodium reabsorption in kidney cortex. Sodium-calcium exchangeable transport system exists in the kidney cortex. Regucalcin mRNA expression in the kidney cortex was enhanced after calcium administration in rats [72]. Presumably, regucalcin regulates calcium transport in the kidney cortex, and this regulation is suppressed through the effect of aldosterone.

Synthetic glucocorticoid dexamethasone has a stimulatory effect on regucalcin mRNA expression in the kidney cortex [72]. Regucalcin gene may have the glucocorticoid response element (GRE) [G(T)G(T)TACA(C)] [72]. Synthetic glucocorticoid dexamethasone has been reported to inhibit sodiumphosphate co-transport in renal epithelial cells; the hormone can diminish renal phosphate re-absorption [73]. This inhibition is mediated through activation of protein kinase $C$ [73]. Regucalcin can inhibit activation of protein kinase $C$ in rat liver cytoplasm [74]. Since dexamethasone administration enhances regucalcin mRNA expression in rat kidney cortex, increased regucalcin may be partly involved in the regulation of mineral metabolism in renal epithelial cells.

The expression of regucalcin mRNA in NRK52E cells in vitro is enhanced by aldosterone, which has a stimulatory effect on re-absorption of sodium in the kidney proximal tubule [68]. In addition, regucalcin mRNA in NRK52E cells is enhanced after culture with dexamethasone [68]. The effect of aldosterone or dexamethasone in the kidney proximal tubule may be partly mediated through regucalcin.

Regucalcin mRNA expression has been shown to suppress in hypertensive state. Intake of saline, which induces hypertensive state, caused an alteration in systemic calcium metabolism that is related to calcium transport in the kidney cortex of rats [75]. Prolonged intake with saline may induce renal disorder with hypertension. The effect of adrenalectomy (ADX) with saline intake, which is a hypertensive factor, on regucalcin mRNA expression in the kidney cortex of rats has been shown [76]. Rats were adrenalectomized, and 48 hours later they were sacrificed. ADX caused a reduction of regucalcin mRNA levels in the kidney cortex [76], suggesting that adrenal glands have a role in regulation of regucalcin gene expression. This reduction, however, was not restored after subcutaneous administration of dexamethasone with an effective dose (100 $\mu \mathrm{g} / 100 \mathrm{~g}$ body weight), which can stimulate regucalcin mRNA expression in the kidney cortex [76]. Intake of saline in ADX rats did not restore ADX-induced suppression of regucalcin mRNA expression in the kidney cortex, suggesting that the suppression of regucalcin mRNA expression in ADX rats is independent on sodium transport in the kidney cortex [76]. Regucalcin mRNA expression has been found to decrease in the kidney cortex of spontaneous hypertensive rats (SHR) as compared with that of control (Wistar-Kyto) rats [76], suggesting an involvement of hypertension.

The mechanism by which various steroid hormones regulate regucalcin mRNA expression in rat kidney cortex has been unknown. Aldosterone- or dexamethasone-induced alteration of regucalcin mRNA expression in rat kidney cortex was completely blocked after simultaneous administration of cycloheximide, an inhibitor of protein synthesis $[72,77]$. This may be partly based on a newly synthesized protein in the kidney cortex; it is possible that the DNA binding proteins (including nuclear receptors) are synthesized after hormonal stimulation. Moreover, calcium, which is an intracellular signaling factor, may be involved in the regucalcin gene expression that is regulated through nuclear receptors.

\section{Hormonal regulation of regucalcin gene expression in other tissues}

Regucalcin has been shown to express in mammary gland and prostate in rat and human and to suppress in human breast and prostate cancers $[49,51]$, and regucalcin gene expressions has been down-regulated by $17 \beta$-estradiol $[49,51]$. The kidney cortex was suppressed after administration of estrogen in rats [72], although estrogen administration caused an enhancement of regucalcin mRNA expression in the liver of rats [50]. This discrepancy of estrogen action in the liver and other tissues may be involved in the differences of DNA binding of estrogen-induced proteins in their tissues. It is possible that the suppressor proteins for regucalcin gene expression exist in the kidney cortex, mammary gland and prostate.

Regucalcin has been shown to express in Leydig and Sertoli 


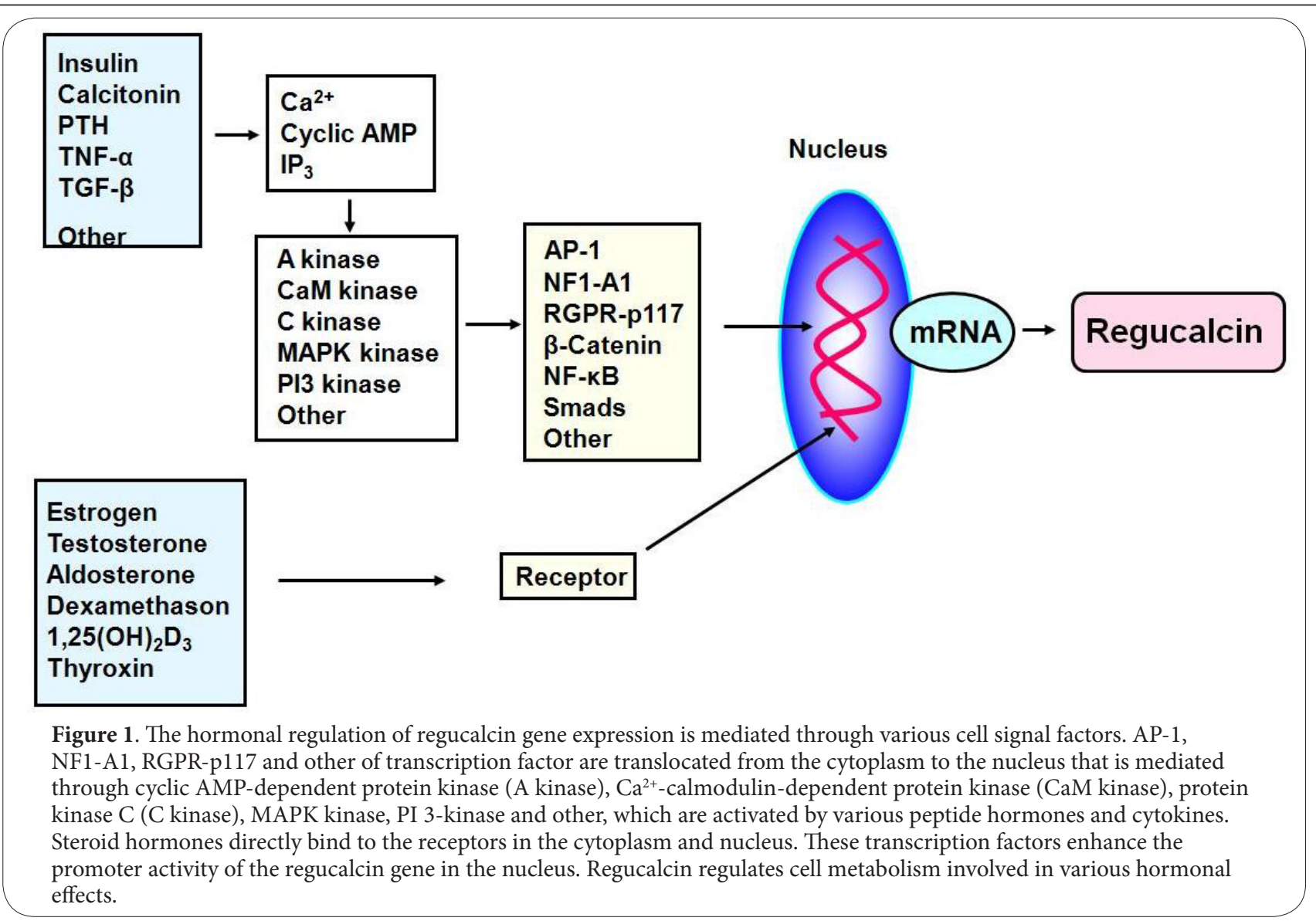

cells, as well as in all types of germ cells of both rat and human testis [77]. Regucalcin expression is age dependent in rat testis and is upregulated by the non-aromatizable androgen (5a-dihydrotestosterone) in rat seminiferous tubules cultured ex vivo [78]. These findings indicate that regucalcin is a novel androgen-target gene in rat testis and that it may have a role in male reproductive function, particularly in the control of spermatogenesis [78].

The effect of various hormones on regucalcin mRNA expression in osteoblastic MC3T3-E1 cells in vitro has been shown [53]. Regucalcin mRNA expression was suppressed after culture with 1,25-dihydroxyvitamin $\mathrm{D}_{3}$ or TNF-a [53], and it was enhanced after culture with PTH, insulin-like growth factor-I (IGF-I) or 17ß-estradiol [53]. The effect of PTH or IGF-I in increasing regucalcin mRNA expression was depressed in presence of staurosporine, an inhibitor of protein kinase $C$, or PD98059, an inhibitor of mitosis-activated protein kinase (MAP kinase), suggesting that the gene expression is enhanced through intracellular signaling factors [53]. Regucalcin may have a role in regulation of osteoblastic cells that stimulate bone formation.

\section{Prospect}

Process of hormonal regulation on regucalcin gene expression is summarized in (Figure 1). Many transcription factors have been identified in regulation of the regucalcin gene promoter activity in the $5^{\prime}$-flanking region of the regucalcin gene. Transcription regulation of regucalcin gene expression is mediated through $\mathrm{Ca}^{2+}$, cyclic AMP, various protein kinases and protein phosphatases that are intracellular signaling factors. Regucalcin mRNA expression has been found to regulate through various hormonal factors (including calcium, insulin, IGF-I, calcitonin, PTH, TNF- $\alpha$, TGF- $\beta$, estrogen, aldosterone, dexamethasone, testosterone, 1,25-dihydroxyvitamin $D_{3}$ and other). Regucalcin may participate in regulation of cell metabolism that is involved in these hormonal effects in various tissues. This may lead to the insight of new development on the physiological role of regucalcin in cell metabolism. Moreover, regucalcin mRNA expression, which is involved in hormonal regulation, is changed in pathophysiological states (carcinogenesis, hyperlipidemia, diabetes, hypertension, osteoporosis and other). The gene therapy with target of the regucalcin gene and the development of drug that modulates regucalcin gene expression may be useful as a therapeutic tool for disease that is implicated to the regucalcin gene. Further studies are expected to determine a clinical aspect of regucalcin for hormonal disease.

\section{Competing interests}

The author declares no competing interests. 
Masayoshi Yamaguchi Hormonal Studies 2013,

\section{Authors' contribution}

The author contributed to the design and conduct of the study, collection, analysis, and interpretation of data, and manuscript writing and has no conflicts of interest.

\section{Acknowledgement}

Regucalcin studies of the author was supported by a Grantin-Aid for Scientific Research (C) No.63571053, No.02671006, No.04671362, No.06672193, No.08672522, No.10672048, No.13672292 and No.17590063 from the Ministry of Education, Science, Sports, and Culture, Japan. Also, the author was awarded the Bounty of Encouragement Foundation in Pharmaceutical Research and the Bounty of the Yamanouchi Foundation for Research on Metabolic Disorders. This study was also supported by the Foundation for Biomedical Research on Regucalcin.

\section{Publication history}

Received: 02-Apr-2013 Revised: 24-Apr-2013

Re-Revised: 26-Apr-2013 Accepted: 08-May-2013

Published: 20-May-2013

\section{References}

1. Williamson JR, Cooper RH and Hoek JB: Role of calcium in the hormonal regulation of liver metabolism. Biochim Biophys Acta 1981, 639:243-95. | Article | PubMed

2. Kraus-Friedmann $\mathrm{N}$ and Feng $\mathrm{L}$ : The role of intracellular $\mathrm{Ca}^{2+}$ in the regulation of gluconeogenesis. Metabolism 1996, 45:389-403. | Article I PubMed

3. Yamaguchi $M$ and Yamamoto T: Purification of calcium binding substance from soluble fraction of normal rat liver. Chem Pharm Bull (Tokyo) 1978, 26:1915-8. | Article | PubMed

4. Yamaguchi M: Physicochemical properties of calcium-binding protein isolated from rat liver cytosol: $\mathrm{Ca}^{2+}$-induced conformational changes. Chem Pharm Bull (Tokyo) 1988, 36:286-90. | Article | PubMed

5. Yamaguchi $\mathrm{M}$ and Mori S: Effect of $\mathrm{Ca}^{2+}$ and $\mathrm{Zn}^{2+}$ on $5^{\prime}$-nucleotidase activity in rat liver plasma membranes: hepatic calcium-binding protein (regucalcin) reverses the $\mathrm{Ca}^{2+}$ effect. Chem Pharm Bull (Tokyo) 1988, 36:321-5. | Article | PubMed

6. Yamaguchi $\mathrm{M}: \mathbf{A}$ novel $\mathrm{Ca}^{2+}$-binding protein regucalcin and calcium inhibition. Regulatory role in liver cell function. In: Kohama K (ed) Calcium inhibition, Japan Sci Soc Press, Tokyo and CRC Press, Boca Raton, 1992, pp19-41.

7. Shimokawa $\mathrm{N}$ and Yamaguchi $\mathrm{M}$ : Molecular cloning and sequencing of the cDNA coding for a calcium-binding protein regucalcin from rat liver. FEBS Lett 1993, 327:251-5. | Article | PubMed

8. Fujita T, Uchida K and Maruyama N: Purification of senescence marker protein-30 (SMP30) and its androgen-independent decrease with age in the rat liver. Biochim Biophys Acta 1992, 1116:122-8. | Article | PubMed

9. Fujita $\mathrm{T}$, Shirasawa $\mathrm{T}$, Uchida $\mathrm{K}$ and Maruyama N: Isolation of cDNA clone encoding rat senescence marker protein-30 (SMP30) and its tissue distribution. Biochim Biophys Acta 1992, 1132:297-305. | Article I PubMed

10. Yamaguchi $M$ : The transcriptional regulation of regucalcin gene expression. Mol Cell Biochem 2011, 346:147-71. | Article | PubMed

11. Shimokawa N, Matsuda Y and Yamaguchi M: Genomic cloning and chromosomal assignment of rat regucalcin gene. Mol Cell Biochem 1995, 151:157-63. | Article | PubMed

12. Thiselton DL, McDowall J, Brandau O, Ramser J, d'Esposito F, Bhattacharya SS, Ross MT, Hardcastle AJ and Meindl A: An integrated, functionally annotated gene map of the DXS8026-ELK1 interval on human Xp11.3-Xp11.23: potential hotspot for neurogenetic disorders. Genomics 2002, 79:560-72. | Article | PubMed

13. Yamaguchi M: Role of regucalcin in maintaining cell homeostasis and function (review). Int J Mol Med 2005, 15:371-89. | Article | PubMed

14. Yamaguchi M: Regucalcin and cell regulation: role as a suppressor protein in signal transduction. Mol Cell Biochem 2011, 353:101-37. | Article I PubMed

15. Kondo Y, Inai Y, Sato Y, Handa S, Kubo S, Shimokado K, Goto S, Nishikimi $\mathrm{M}$, Maruyama $\mathrm{N}$ and Ishigami A: Senescence marker protein $\mathbf{3 0}$ functions as gluconolactonase in L-ascorbic acid biosynthesis, and its knockout mice are prone to scurvy. Proc Natl Acad Sci U S A 2006, 103:5723-8. | Article | PubMed Abstract | PubMed Full Text

16. Yamaguchi M: Regucalcin and metabolic disorders: osteoporosis and hyperlipidemia are induced in regucalcin transgenic rats. Mol Cell Biochem 2010, 341:119-33. | Article | PubMed

17. Yamaguchi $M$ and Murata $T$ : Involvement of regucalcin in lipid metabolism and diabetes. Metabolism 2013. | Article | PubMed

18. Shimokawa N, Isogai M and Yamaguchi M: Specific species and tissue differences for the gene expression of calcium-binding protein regucalcin. Mol Cell Biochem 1995, 143:67-71. | Article I PubMed

19. Yamaguchi M, Makino R and Shimokawa N: The 5' end sequences and exon organization in rat regucalcin gene. Mol Cell Biochem 1996, 165:145-50. | Article | PubMed

20. Shimokawa $\mathrm{N}$ and Yamaguchi M: Calcium administration stimulates the expression of calcium-binding protein regucalcin mRNA in rat liver. FEBS Lett 1992, 305:151-4. | Article | PubMed

21. Yamaguchi $M$ and Isogai $M$ : Tissue concentration of calcium-binding protein regucalcin in rats by enzyme-linked immunoadsorbent assay. Mol Cell Biochem 1993, 122:65-8. | Article | PubMed

22. Murata T and Yamaguchi M: Tissue-specific binding of nuclear factors to the 5'-flanking region of the rat gene for calcium-binding protein regucalcin. Mol Cell Biochem 1998, 178:305-10. I PubMed

23. Murata T and Yamaguchi M: Promoter characterization of the rat gene for $\mathrm{Ca}^{2+}$-binding protein regucalcin. Transcriptional regulation by signaling factors. J Biol Chem 1999, 274:1277-85. | Article | PubMed

24. Murata $\mathrm{T}$ and Yamaguchi $\mathrm{M}: \mathrm{Ca}^{2+}$ administration stimulates the binding of AP-1 factor to the 5'-flanking region of the rat gene for the Ca2+-binding protein regucalcin. Biochem J 1998, 329 ( Pt 1):157-63. | PubMed Abstract | PubMed Full Text

25. Curran $T$ Fos and June: intermediary transcription factors. In: Cohen $P$, Foulkes JG eds) The Hormonal Control of Gene Transcription, Elsevier, New York, 1991, pp295-308.

26. Rahmsdorf HJ and Herrlich P: Regulation of gene expression by tumor promoters. Pharmacol Ther 1990, 48:157-88. | Article I PubMed

27. Karin $\mathrm{M}$ and Smeal T: Control of transcription factors by signal transduction pathways: the beginning of the end. Trends Biochem Sci 1992, 17:418-22. | Article | PubMed

28. Meyer TE and Habener JF: Cyclic adenosine 3',5'-monophosphate response element binding protein (CREB) and related transcriptionactivating deoxyribonucleic acid-binding proteins. Endocr Rev 1993, 14:269-90. | Article | PubMed

29. Roesler WJ, Vandenbark GR and Hanson RW: Cyclic AMP and the induction of eukaryotic gene transcription. J Biol Chem 1988, 263:90636. | Article | PubMed

30. Truss $M$ and Beato $M$ : Steroid hormone receptors: interaction with deoxyribonucleic acid and transcription factors. Endocr Rev 1993 14:459-79. | Article | PubMed

31. Nakajima M, Murata T and Yamaguchi M: Expression of calcium-binding protein regucalcin mRNA in the cloned rat hepatoma cells (H4-II-E) is stimulated through $\mathrm{Ca}^{2+}$ signaling factors: involvement of protein kinase C. Mol Cell Biochem 1999, 198:101-7. I Article | PubMed

32. Yamaguchi $M$ and Nakajima M: Involvement of intracellular signaling factors in the serum-enhanced $\mathrm{Ca}^{2+}$-binding protein regucalcin mRNA expression in the cloned rat hepatoma cells (H4-II-E). J Cell Biochem 1999, 74:81-9. | Article | PubMed

33. Murata $T$, Shinya $N$ and Yamaguchi $M$ : Expression of calcium-binding protein regucalcin mRNA in the cloned human hepatoma cells (HepG2): stimulation by insulin. Mol Cell Biochem 1997, 175:163-8. | Article | PubMed

34. Misawa $\mathrm{H}$ and Yamaguchi M: Involvement of hepatic nuclear factor I binding motif in transcriptional regulation of $\mathrm{Ca}^{(2+)}$-binding protein 
regucalcin gene. Biochem Biophys Res Commun 2000, 269:270-8. Article | PubMed

35. Ritzenthaler JD, Goldstein RH, Fine A, Lichtler A, Rowe DW and Smith BD: Transforming-growth-factor-beta activation elements in the distal promoter regions of the rat alpha 1 type I collagen gene. Biochem J 1991, 280 ( Pt 1):157-62. | PubMed Abstract | PubMed Full Text

36. Ogata $Y$, Niisato N, Furuyama S, Cheifetz S, Kim RH, Sugiya H and Sodek J: Transforming growth factor-beta 1 regulation of bone sialoprotein gene transcription: identification of a TGF-beta activation element in the rat BSP gene promoter. J Cell Biochem 1997, 65:501-12. | Article | PubMed

37. Krohn K, Rozovsky I, Wals P, Teter B, Anderson CP and Finch CE: Glial fibrillary acidic protein transcription responses to transforming growth factor-beta1 and interleukin-1beta are mediated by a nuclear factor-1like site in the near-upstream promoter. J Neurochem 1999, 72:1353-61. | Article | PubMed

38. Lee $M$, Song H, Yu S, Lee $K$ and Park JS: A 40-kDa NF1-like protein, not YY1, binds to the rat $\mathrm{p} 53$ promoter for transactivation in various rat organs. Biochem Cell Biol 1999, 77:209-14. I Article I PubMed

39. Misawa $\mathrm{H}$ and Yamaguchi $\mathrm{M}$ : Intracellular signaling factors--enhanced hepatic nuclear protein binding to TTGGC sequence in the rat regucalcin gene promoter: involvement of protein phosphorylation. Biochem Biophys Res Commun 2000, 279:275-81. | Article | PubMed

40. Hunter T: Protein kinases and phosphatases: the yin and yang of protein phosphorylation and signaling. Cell 1995, 80:225-36. | Article | PubMed

41. Misawa $\mathrm{H}$ and Yamaguchi $\mathrm{M}$ : Identification of transcription factor in the promoter region of rat regucalcin gene: binding of nuclear factor I-A1 to TTGGC motif. J Cell Biochem 2002, 84:795-802. | Article | PubMed

42. Misawa $\mathrm{H}$ and Yamaguchi $\mathrm{M}$ : Molecular cloning and sequencing of the cDNA coding for a novel regucalcin gene promoter region-related protein in rat, mouse and human liver. Int J Mol Med 2001, 8:513-20. | Article I PubMed

43. Misawa $\mathrm{H}$ and Yamaguchi $\mathrm{M}$ : Gene expression for a novel protein RGPR-p117 in various species: the stimulation by intracellular signaling factors. J Cell Biochem 2002, 87:188-93. I Article I PubMed

44. Yamaguchi M: Novel protein RGPR-p117: its role as the regucalcin gene transcription factor. Mol Cell Biochem 2009, 327:53-63. | Article | PubMed

45. Sawada N and Yamaguchi M: Overexpression of RGPR-p117 enhances regucalcin gene expression in cloned normal rat kidney proximal tubular epithelial cells. Int J Mol Med 2005, 16:1049-55. | Article | PubMed

46. Sawada N and Yamaguchi M: Overexpression of RGPR-p117 enhances regucalcin gene promoter activity in cloned normal rat kidney proximal tubular epithelial cells: involvement of TTGGC motif. J Cell Biochem 2006, 99:589-97. | Article | PubMed

47. Nejak-Bowen KN, Zeng G, Tan X, Cieply B and Monga SP: Beta-catenin regulates vitamin $\mathrm{C}$ biosynthesis and cell survival in murine liver. $J$ Biol Chem 2009, 284:28115-27. | Article | PubMed Abstract | PubMed Full Text

48. Yamaguchi M, Otomo Y, Uchiyama S and Nakagawa T: Hormonal regulation of regucalcin mRNA expression in osteoblastic MC3T3-E1 cells. Int J Mol Med 2008, 21:771-5. | Article | PubMed

49. Yamaguchi $M$ and Oishi K: 17 beta-Estradiol stimulates the expression of hepatic calcium-binding protein regucalcin mRNA in rats. Mol Cell Biochem 1995, 143:137-41. I PubMed

50. Tsai M-J, O'Malley BW: Mechanism of regulation of gene transcription by steroid recectors. In: P. Cohen, J. G. Foulkes (eds). The Hormonal Control of Gene Transcription. Elservier, Amsterdam, 1991, pp. 101-128.

51. Maia CJ, Santos CR, Schmitt F and Socorro S: Regucalcin is expressed in rat mammary gland and prostate and down-regulated by $17 \mathrm{beta}-$ estradiol. Mol Cell Biochem 2008, 311:81-6. I Article I PubMed

52. Nejak-Bowen KN, Zeng G, Tan X, Cieply B and Monga SP: Beta-catenin regulates vitamin $C$ biosynthesis and cell survival in murine liver. $J$ Biol Chem 2009, 284:28115-27. | Article I PubMed Abstract | PubMed Full Text
53. Yamaguchi M, Otomo $\mathrm{Y}$, Uchiyama $\mathrm{S}$ and Nakagawa T: Hormonal regulation of regucalcin mRNA expression in osteoblastic MC3T3-E1 cells. Int J Mol Med 2008, 21:771-5. I Article I PubMed

54. Rath B, Pandey RS, Debata PR, Maruyama N and Supakar PC: Molecular characterization of senescence marker protein-30 gene promoter: identification of repressor elements and functional nuclear factor binding sites. BMC Mol Biol 2008, 9:43. | Article | PubMed Abstract | PubMed Full Text

55. Isogai $M$ and Yamaguchi M: Calcium administration increases calciumbinding protein regucalcin concentration in the liver of rats. $\mathrm{Mol} \mathrm{Cell}$ Biochem 1995, 143:53-8. I Article I PubMed

56. Shimokawa $\mathrm{N}$ and Yamaguchi M: Expression of hepatic calcium-binding protein regucalcin mRNA is mediated through $\mathrm{Ca}^{2+} /$ calmodulin in rat liver. FEBS Lett 1993, 316:79-84. I Article I PubMed

57. Yamaguchi $\mathrm{M}$ and Ueoka S: Expression of calcium-binding protein regucalcin mRNA in fetal rat liver is stimulated by calcium administration. Mol Cell Biochem 1998, 178:283-7. | Article I PubMed

58. Yamaguchi M, Takei $Y$ and Yamamoto $T$ : Effect of thyrocalcitonin on calcium concentration in liver of intact and thyroparathyroidectomized rats. Endocrinology 1975, 96:1004-8. | Article I PubMed

59. Yamaguchi M: Stimulatory effect of calcitonin on $\mathrm{Ca}^{2+}$ inflow in isolated rat hepatocytes. Mol Cell Endocrinol 1991, 75:65-70. | Article I PubMed

60. Yamaguchi $\mathrm{M}$ and Imase $\mathrm{M}$ : Hormonal regulation of biliary calcium excretion in rats: inhibition of calcitonin action by alpha 1-adrenergic stimulation. Horm Metab Res 1988, 20:221-4. I Article I PubMed

61. Yamaguchi $\mathrm{M}$, Oishi $\mathrm{K}$ and Isogai $\mathrm{M}$ : Expression of hepatic calciumbinding protein regucalcin mRNA is elevated by refeeding of fasted rats: involvement of glucose, insulin and calcium as stimulating factors. $\mathrm{Mol}$ Cell Biochem 1995, 142:35-41. | Article | PubMed

62. Yamaguchi $M$ and Kanayama Y: Enhanced expression of calcium-binding protein regucalcin mRNA in regenerating rat liver. J Cell Biochem 1995, 57:185-90. | Article | PubMed

63. Piol MR, Berchtold MW, Bachs $\mathrm{O}$ and Heizmann CW: Increased calmodulin synthesis in the pre-replicative phase of rat liver regeneration. FEBS Lett 1988, 231:445-50. I Article I PubMed

64. Baffy G, Yang L, Michalopoulos GK and Williamson JR: Hepatocyte growth factor induces calcium mobilization and inositol phosphate production in rat hepatocytes. J Cell Physiol 1992, 153:332-9. | Article | PubMed

65. Yamaguchi M, Kanayama $\mathrm{Y}$ and Shimokawa N: Expression of calciumbinding protein regucalcin mRNA in rat liver is stimulated by calcitonin: the hormonal effect is mediated through calcium. Mol Cell Biochem 1994, 136:43-8. | Article | PubMed

66. Ueoka S and Yamaguchi M: Sexual difference of hepatic calcium-binding protein regucalcin mRNA expression in rats with different ages: effect of ovarian hormone. Biol Pharm Bull 1998, 21:405-7. I Pdf I PubMed

67. Yamaguchi $\mathrm{M}$ and Kurota $\mathrm{H}$ : Expression of calcium-binding protein regucalcin mRNA in the kidney cortex of rats: the stimulation by calcium administration. Mol Cell Biochem 1995, 146:71-7. | Article | PubMed

68. Murata $\mathrm{T}$ and Yamaguchi M: Binding of kidney nuclear proteins to the 5 -flanking region of the rat gene for $\mathrm{Ca}^{2+}$-binding protein regucalcin: involvement of $\mathrm{Ca}^{2+} /$ calmodulin signaling. Mol Cell Biochem 1999, 199:35-40. | Article | PubMed

69. Misawa $\mathrm{H}$ and Yamaguchi M: Involvement of nuclear factor-1 (NF1) binding motif in the regucalcin gene expression of rat kidney cortex: the expression is suppressed by cisplatin administration. Mol Cell Biochem 2001, 219:29-37. | Article I PubMed

70. Nakagawa T and Yamaguchi M: Hormonal regulation on regucalcin mRNA expression in cloned normal rat kidney proximal tubular epithelial NRK52E cells. J Cell Biochem 2005, 95:589-97. | Article | PubMed

71. Nakagawa T and Yamaguchi M: Overexpression of regucalcin suppresses cell response for tumor necrosis factor-alpha or transforming growth factor-beta1 in cloned normal rat kidney proximal tubular epithelial NRK52E cells. J Cell Biochem 2007, 100:1178-90. | Article | PubMed 
Masayoshi Yamaguchi Hormonal Studies 2013,

72. Kurota $\mathrm{H}$ and Yamaguchi M: Steroid hormonal regulation of calciumbinding protein regucalcin mRNA expression in the kidney cortex of rats. Mol Cell Biochem 1996, 155:105-11. | Article I PubMed

73. Vrtovsnik F, Jourdain M, Cherqui G, Lefebvre J and Friedlander G: Glucocorticoid inhibition of Na-Pi cotransport in renal epithelial cells is mediated by protein kinase C. J Biol Chem 1994, 269:8872-7. | Pdf | PubMed

74. Yamaguchi $M$ and Mori S: Inhibitory effect of calcium-binding protein regucalcin on protein kinase $\mathrm{C}$ activity in rat liver cytosol. Biochem Med Metab Biol 1990, 43:140-6. | Article | PubMed

75. Shinya $\mathrm{N}$ and Yamaguchi $\mathrm{M}$ : Alterations in $\mathrm{Ca}^{2+}$-ATPase activity and calcium-binding protein regucalcin mRNA expression in the kidney cortex of rats with saline ingestion. Mol Cell Biochem 1997, 170:17-22. | Article I PubMed

76. Shinya $\mathrm{N}$, Kurota $\mathrm{H}$, Yamaguchi $\mathrm{M}$ : Calcium-binding protein regucalcin mRNA expression in the kidney cortex is suppressed by saline ingestion in rats. Mol Cell Biochem 1996, 162:139-144. | Article

77. Laurentino SS, Correia S, Cavaco JE, Oliveira PF, Rato L, Sousa M, Barros $A$ and Socorro $S$ : Regucalcin is broadly expressed in male reproductive tissues and is a new androgen-target gene in mammalian testis. Reproduction 2011, 142:447-56. I Article I PubMed

78. Marques R, Maia CJ, Vaz C, Correia S and Socorro S: The diverse roles of calcium-binding protein regucalcin in cell biology: from tissue expression and signalling to disease. Cell Mol Life Sci 2013. | Article | PubMed

\section{Citation:}

Yamaguchi M: Hormonal regulation of regucalcin gene expression: involvement in cell metabolism. Hormonal Studies 2013, 1:1. http://dx.doi.org/10.7243/2052-8000-1-1 